\title{
Xanthine oxidase activity in patients with age-related cataract associated with hypertension
}

\author{
B. Kisic ${ }^{1}$, D. Miric ${ }^{1}$, L. Zoric ${ }^{2}$, J.V. Rasic ${ }^{3}$, R. Grbic ${ }^{4}$, Lj.M. Popovic ${ }^{5}$ and A.M. Arsic ${ }^{6}$ \\ ${ }^{1}$ Institute of Biochemistry, Faculty of Medicine, University of Pristina, Kosovska Mitrovica, Serbia \\ ${ }^{2}$ Clinic for Eye Diseases, Faculty of Medicine, University of Pristina, Kosovska Mitrovica, Serbia \\ ${ }^{3}$ Institute of Pharmacology, Faculty of Medicine, University of Pristina, Kosovska Mitrovica, Serbia \\ ${ }^{4}$ Clinic for General and Orthopedics Surgery, Faculty of Medicine, University of Pristina, Kosovska Mitrovica, Serbia \\ ${ }^{5}$ Institute of Pathophysiology, Faculty of Medicine, University of Pristina, Kosovska Mitrovica, Serbia \\ ${ }^{6}$ Department for Laboratory Investigation, Railway Health Care Institute, Novi Sad, Serbia
}

\begin{abstract}
Reactive oxygen species and lipid peroxidation are important factors that contribute to the development of age-related cataract. The study included 130 patients with age-related cataract, 69 of whom were diagnosed with hypertension (HT), 20 with hypertension and type 2 diabetes mellitus (DM), and 41 had no accompanying condition. The following parameters were measured in the serum of the examinees: products of lipid peroxidation malondialdehyde (MDA) and lipofuscin-like fluorophores (LLF), activity of prooxidative enzymes xanthine oxidase (XO) and myeloperoxidase (MPO), antioxidant enzymes superoxide dismutase (SOD) and glutathione peroxidase (GPx), the concentration of thiol groups, and the ferric reducing activity of plasma. The activity of prooxidative enzymes $\mathrm{XO}$ and MPO was higher in the plasma of patients with $\mathrm{HT}$ (XO=9.0 $\pm 1.2 \mathrm{U} / \mathrm{L}$; MPO= $77.3 \pm 8.4 \mathrm{U} / \mathrm{L})$ and with $\mathrm{HT}$ and $\mathrm{DM}(\mathrm{XO}=11.9 \pm 0.9 \mathrm{U} / \mathrm{L} ; \mathrm{MPO}=89.5 \pm 5.0 \mathrm{U} / \mathrm{L})$ compared to patients with age-related cataract $(\mathrm{XO}=6.2 \pm 0.9 \mathrm{U} / \mathrm{L} ; \mathrm{MPO}=52.4 \pm 6.3 \mathrm{U} / \mathrm{L} ; \mathrm{P}<0.01)$. Our research has shown that patients with age-related cataract and hypertension were exposed to increased oxidative damage of biomolecules, based on the increased plasma LLF and MDA content and decreased levels of thiol groups. Oxidative changes of biomolecules in these patients were associated with increased activity of the XO, MPO, and GPx enzymes and a lower extracellular SOD activity and total ferric reductive ability of plasma.
\end{abstract}

Key words: Age-related cataract; Hypertension; Xanthine oxidase; Myeloperoxidase

\section{Introduction}

Oxidative modifications of various biomolecules constantly occur in tissues throughout an individual's life, but in patients with age-related cataract (ARC), oxidative modifications of proteins and lipids are obvious and a dominant metabolic feature and pathological substrate of disease (1). The development of ARC involves multiple though inter-related risk factors, including ageing process, exposure to environmental and intrinsic oxidants, diet and lifestyle factors, as well as several systemic disorders, such as diabetes mellitus (DM) and hypertension (HT) $(2,3)$.

The origin of HT is also multifactorial, and currently not all underlying molecular mechanisms are known. Still, numerous studies indicate that reactive oxygen species (ROS) are implicated in vascular redox signaling, regulation of vascular tone, and remodeling of blood vessel walls. Conversely, increased presence of oxidants resulting in oxidative stress probably contributes to endothelial dysfunction and the development of hypertension (4). In endothelial cells, redox state is primarily regulated by a dynamic balance between endogenously synthesized nitric oxide (NO) and superoxide anion radical $\left(\mathrm{O}_{2}{ }^{-}\right)$, which is the main ROS within vasculature. NO is a potent vasodilator substance and its diminished availability upon reaction with $\mathrm{O}_{2}{ }^{\bullet-}$ causes increased resistance of arterioles, eventually leading to the development of hypertension (5).

Although there could be several sources of oxidants in the vasculature implicated in hypertension, xanthine oxidase $(\mathrm{XO})$ has received special attention in past years. In physiological conditions, this xanthine-degrading enzyme exists as a dehydrogenase, utilizing $\mathrm{NAD}^{+}$as an electron acceptor in the course of conversion of hypoxanthine and xanthine to uric acid. However, limited proteolysis, oxidation of critical thiol-groups, or hypoxic conditions can induce the conversion of the enzyme to the oxidase form (6). Both xanthine dehydrogenase and XO utilize xanthine and hypoxanthine as substrates to produce uric acid and ROS. 
It has been previously demonstrated that XO-derived oxidants have a strong impact on arteriolar tone and blood pressure in spontaneously hypertensive animals (7), and that $\mathrm{XO}$ activity represented a significant risk factor of hypertension in normotensive younger adults (8). Given that hypertension is a significant risk factor of ARC development, and that we previously demonstrated involvement of $\mathrm{XO}$ in oxidative damage and earlier development of ARC among diabetic subjects (9), our current study aimed to investigate the relationship between $\mathrm{XO}$ and hypertension in patients with ARC.

\section{Patients and Methods}

This study included 130 patients with ARC, scheduled for cataract surgery in the Department for Ophthalmology, Health Center Kosovska Mitrovica, Serbia. Of all included patients, 41 had ARC only, 69 had ARC and hypertension, and 20 patients had ARC, HT, and type $2 \mathrm{DM}$. The study protocol was approved by the Ethics Committee of the Medical Faculty in accordance with the Helsinki Declaration. Informed consent was obtained from all individual participants included in the study. Patients with hypertension were identified by blood pressure of more than $140 / 90 \mathrm{mmHg}$. Their blood pressure was recorded by an auscultatory method using a sphygmomanometer.

Venous blood was collected after an overnight fasting into tubes containing solid dipotassium EDTA or into plain tubes. The tubes were centrifuged at $1351 \mathrm{~g}$ for $10 \mathrm{~min}$ at $4^{\circ} \mathrm{C}$, serum or plasma samples were separated, and aliquoted samples were immediately stored at $-80^{\circ} \mathrm{C}$. All chemicals used in this study were of analytical grade.

Serum lipid profile, total cholesterol (TC), high-density lipoprotein cholesterol (HDL-C), and triglycerides (TAG) were measured using commercial enzymatic kits (Roche/ Boehringer, Germany) by automated analyzer (Hitachi Instruments, Japan). Low-density lipoprotein (LDL)-cholesterol was derived according to the Friedewald's equation. Concentration of glycated hemoglobin A1C (HbA1C) was assessed by turbidimetric inhibition immunoassay. Body mass index (BMI) was calculated as the ratio between body weight in $\mathrm{kg}$ and the square of body height in $\mathrm{m}^{2}$.

The concentration of malondialdehyde (MDA), which is a relatively stable lipid peroxidation marker, was measured by a method according to Ledwozyw et al. (10) on a Safas UVIVIS spectrophotometer (Safas 2, Monaco). Absorbance of the complex produced in the reaction of MDA with 2-thiobarbituric acid (2-thiobarbituric acid, $70 \mathrm{mM}$; $\mathrm{NaOH}, 50 \mathrm{mM}$ ) was measured at $\lambda=532 \mathrm{~nm}$. The lipofuscin-like fluorophores (LLF) were measured at $360 / 430 \mathrm{~nm}$ (excitation/emission) in a fluorescent photometer equipped with a xenon lamp (Jenway 6285, Barloworld Scientific Ltd, UK), after delipidation of plasma with ethanol/ether $(3 / 1, v / v)(11)$.

$\mathrm{XO}$ activity was measured by spectrophotometry based on the change in absorbance at $290 \mathrm{~nm}$, at the conversion of xanthine to uric acid (xanthine, $3 \mathrm{mM}$; in $0.1 \mathrm{M} \mathrm{NaOH} /$ glycine buffer) (12). Plasma myeloperoxidase (MPO) activity was assayed in the system of 4-aminoantipyrine and phenol with hydrogen peroxide $(1.7 \mathrm{mM})$ as the substrate, by monitoring the production of quinoneimine at $\lambda=505 \mathrm{~nm}$, as described by Metcalf et al. (13). One unit of MPO activity was defined as the amount of enzyme degrading $1 \mu \mathrm{mol}$ of hydrogen peroxide per minute at $25^{\circ} \mathrm{C}$.

Activity of SOD was measured by the method of Misra and Fridovich (14) based on the ability of SOD to inhibit auto-oxidation of adrenaline, with adrenaline bitartarate (7 mM) as a substrate, at alkaline $\mathrm{pH}(\mathrm{pH} 10.2)$. The increase in absorbance of adrenochrome was monitored at $25^{\circ} \mathrm{C}$ for $3 \mathrm{~min}$ at $\lambda=480 \mathrm{~nm}$. One unit of SOD activity was defined as the amount of enzyme that inhibits auto-oxidation of $5 \mathrm{mmol}$ adrenaline by $50 \%$. Plasma GPx activity was measured using cumene hydroperoxide as a substrate, the method of Chin et al. (15). The absorbance of the reaction product was measured at $412 \mathrm{~nm}$.

The concentration of serum -SH groups was measured with Ellman's reagent (DTNB) (16). Protein -SH groups reduced DTNB [5,5'-dithiobis-(2-nitrobenzoic acid)] producing a yellow-colored anion of 5-thio-2-nitrobenzoic acid $\left(\mathrm{TNB}^{-}\right)$. The absorbance was read at $412 \mathrm{~nm}$ on the Safas UVNIS spectrophotometer. The ferric reducing/antioxidant power assay (FRAP) is a colorimetric method for testing the ability of ferric reductive plasma, where at low $\mathrm{pH}$, $\mathrm{Fe}^{+3}$-TPTZ reduces to $\mathrm{Fe}^{+2}-\mathrm{TPTZ}$ giving a blue color with maximum absorbance at $593 \mathrm{~nm}$ (17).

\section{Statistical analysis}

Descriptive statistical methods, methods for testing statistical hypotheses, and methods for testing dependence were used for the analysis of primary data. Descriptive statistical methods used were the following: measure of central tendency (arithmetic mean), measure of variability (standard deviation), and relative numbers. The methods used for testing statistical hypotheses were the $t$-test for two independent samples and the single-factor ANOVA with the post hoc Tukey's test. The method used for dependence analysis was the Pearson linear correlation coefficient. Hypotheses were tested at the level of statistical significance (alpha level) of 0.01 and 0.05 . The software program SPSS Statistics 22 (USA) was used for statistical analysis of the results.

\section{Results}

Demographic and clinical characteristics and biochemical indicators of lipids and glycemic status in the examined patients are presented in Table 1.

Table 2 shows the indicators of oxidative stress in serum of examined patients, markers of lipid peroxidation MDA and LLF, the activity of the pro-oxidative enzymes $\mathrm{XO}$ and MPO, the activity of antioxidant enzymes SOD and GPx, the concentration of -SH groups, and FRAP. 
Table 1. Basic demographical, clinical, and biochemical characteristics of patients.

\begin{tabular}{lcccc}
\hline & ARC & ARC and HT & ARC, HT, and DM & P value \\
\hline Number of subjects, $\mathrm{n} \mathrm{( \% )}$ & $41(32 \%)$ & $69(53 \%)$ & $20(15 \%)$ & \\
Gender, $\mathrm{n}(\%)$ & & & 0.864 \\
$\quad$ Male & $21(17)$ & $39(30)$ & $9(7)$ & \\
$\quad$ Female & $20(15)$ & $30(23)$ & $11(8)$ & \\
Age (years) & $71.4 \pm 7.3$ & $71.3 \pm 6.0$ & $72.1 \pm 6.9$ & 0.893 \\
Mean SBP (mmHg) & $120 \pm 10$ & $152 \pm 18$ & $154 \pm 13$ & $<0.01$ \\
Mean DBP (mmHg) & $75 \pm 5$ & $95 . \pm 10$ & $97 \pm 11$ & $<0.01$ \\
Body mass index (kg/m $\left.{ }^{2}\right)$ & $23.9 \pm 2.5$ & $24.5 \pm 2.8$ & $25.2 \pm 2.5$ & 0.083 \\
Baseline glucose $(\mathrm{mmol} / \mathrm{L})$ & $5.4 \pm 1.3$ & $5.5 \pm 1.5$ & $7.9 \pm 1.9$ & $<0.01$ \\
HbA1C $(\%$ of hemoglobin) & $5.3 \pm 1.8$ & $5.6 \pm 1.5$ & $9.1 \pm 2.4$ & $<0.01$ \\
Total cholesterol (mmol/L) & $4.7 \pm 0.3$ & $6.8 \pm 0.4$ & $7.2 \pm 0.5$ & $<0.01$ \\
HDL-cholesterol (mmol/L) & $1.6 \pm 0.3$ & $0.9 \pm 0.2$ & $0.9 \pm 0.4$ & $<0.01$ \\
LDL-cholesterol (mmol/L) & $3.0 \pm 0.5$ & $6.0 \pm 0.5$ & $6.3 \pm 0.8$ & $<0.01$ \\
Triacylglycerols (mmol/L) & $1.9 \pm 0.5$ & $2.4 \pm 0.5$ & $2.7 \pm 0.4$ & $<0.01$ \\
\hline
\end{tabular}

Data are reported as means $\pm S D$ or number and percentage. ARC: age-related cataract; $H T$ : hypertension; DM: diabetes mellitus; HbA1C: glycated hemoglobin A; SBP: systolic blood pressure; DBP: diastolic blood pressure; LDL: low-density lipoprotein; HDL: high-density lipoprotein. Statistical analysis was done with ANOVA the post hoc Tukey's test.

Table 2. Markers of lipid peroxidation and antioxidant enzyme activities in the blood of patients.

\begin{tabular}{lcccc}
\hline & ARC & ARC and HT & ARC, HT, and DM & P value \\
\hline Number of subjects, $\mathrm{n}(\%)$ & $41(32 \%)$ & $69(53.0 \%)$ & $20(15 \%)$ & \\
XO $(\mathrm{U} / \mathrm{L})$ & $6.2 \pm 0.9$ & $9.4 \pm 1.3$ & $11.9 \pm 0.9$ & $<0.01$ \\
MPO $(\mathrm{U} / \mathrm{L})$ & $52.4 \pm 6.3$ & $77.3 \pm 8.4$ & $89.5 \pm 5.0$ & $<0.01$ \\
LLF $(\mathrm{RFU} / \mathrm{mL})$ & $48.4 \pm 5.2$ & $79.7 \pm 11.0$ & $92.3 \pm 4.5$ & $<0.01$ \\
MDA $(\mu \mathrm{mol} / \mathrm{L})$ & $4.6 \pm 0.8$ & $6.6 \pm 0.5$ & $8.0 \pm 0.6$ & $<0.01$ \\
SH groups $(\mu \mathrm{mol} / \mathrm{L})$ & $501.4 \pm 45.6$ & $400.6 \pm 34.6$ & $312.7 \pm 40.6$ & $<0.01$ \\
FRAP $(\mu \mathrm{mol} / \mathrm{L})$ & $774.2 \pm 100.1$ & $613.9 \pm 43.9$ & $575.9 \pm 67.6$ & $<0.01$ \\
GPx $(\mathrm{U} / \mathrm{L})$ & $185.2 \pm 12.5$ & $235.2 \pm 19.7$ & $287.7 \pm 11.9$ & $<0.01$ \\
SOD $(\mathrm{U} / \mathrm{L})$ & $38.7 \pm 1.2$ & $29.9 \pm 3.0$ & $24.1 \pm 2.7$ & $<0.01$ \\
\hline
\end{tabular}

Data are reported as means $\pm \mathrm{SD}$. ARC: age-related cataract; $\mathrm{HT}$ : hypertension; DM: diabetes mellitus; XO: xanthine oxidase; MPO: myeloperoxidase; LLF: lipofuscin-like fluorophores; MDA: malondialdehyde; $\mathrm{SH}$ : thiol; FRAP: ferric reducing/antioxidant power assay; GPx: glutathione peroxidase; SOD: superoxide dismutase. Statistical analysis was done with ANOVA the post hoc Tukey's test.

The activity of oxidant enzymes XO $(6.2 \pm 0.9 \mathrm{U} / \mathrm{L}$; $\mathrm{P}<0.01)$ and MPO $(52.4 \pm 6.3 \mathrm{U} / \mathrm{L} ; \mathrm{P}<0.01)$ in the serum of patients with age-related cataract was significantly lower compared to patients with age-related cataract and $\mathrm{HT}(\mathrm{XO}=9.0 \pm 1.2 \mathrm{U} / \mathrm{L} ; \mathrm{MPO}=77.3 \pm 8.4 \mathrm{U} / \mathrm{L})$ and patients with $\mathrm{HT}$ and $\mathrm{DM}(\mathrm{XO}=11.9 \pm 0.9 \mathrm{U} / \mathrm{L} ; \mathrm{MPO}=89.5 \pm 5.0 \mathrm{U} / \mathrm{L})$. Also, there was a significant difference between the activities of both oxidant enzymes in the serum of patients with a HT and patients with HT and DM $(\mathrm{P}<0.01)$.

Significantly lower activity of antioxidant enzymes SOD and GPx was measured in patients with $\mathrm{HT}$ and DM compared to patients with only ARC.
The plasma of patients diagnosed with HT and DM in addition to ARC showed the lowest ferric reductive ability $(575.9 \pm 67.6 \mu \mathrm{mol} / \mathrm{L})$ compared to the patients with ARC and HT $(613.9 \pm 43.9 \mu \mathrm{mol} / \mathrm{L})$ and those with age-related cataract $(774.2 \pm 100.1 \mu \mathrm{mol} / \mathrm{L} ; \mathrm{P}<0.01)$.

The highest concentration of sulfhydryl groups was measured in the plasma of normotensive ARC patients $(501.4 \pm 45.6 \mu \mathrm{mol} / \mathrm{L})$ compared to patients with HT $(400.6 \pm 34.6 \mu \mathrm{mol} / \mathrm{L})$ and those with HT and DM (312.7 \pm $40.6 \mu \mathrm{mol} / \mathrm{L} ; \mathrm{P}<0.01)$.

There was a significant positive correlation between plasma concentration of lipofuscin-like fluorophores (RFU/mL) 


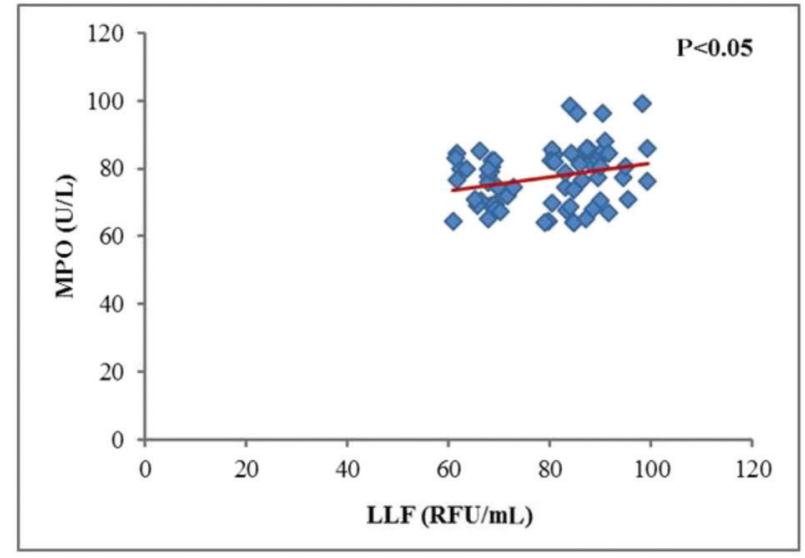

Figure 1. Correlation between lipofuscin-like fluorophores (LLF) and myeloperoxidase (MPO) in serum of patients with hypertension and age-related cataract $(n=69, r=0.255, P<0.05)$.

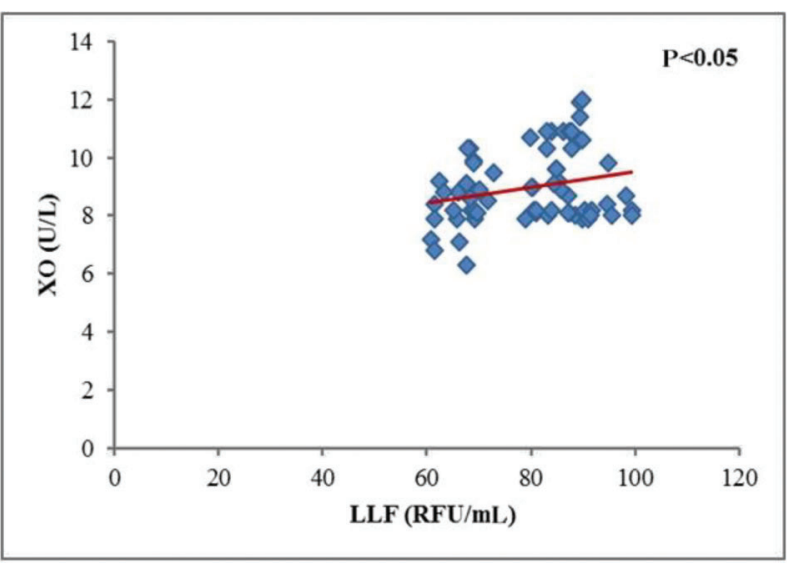

Figure 2. Correlation between lipofuscin-like fluorophores (LLF) and xanthine oxidase $(X O)$ in serum of patients with hypertension and age-related cataract $(n=69, r=0.244, P<0.05)$.

and GPx activity $(U / L)(n=130, r=0.750, P<0.01)$, between the concentration of LLF (RFU/mL) and XO activity (U/L; $n=130, r=0.793, P<0.01)$, and between the concentration of MDA $(\mu \mathrm{mol} / \mathrm{L})$ and GPx activity $(U / L ; n=130, r=0.789$, $P<0.01)$.

A significant correlation between the LLF and MPO (U/L; $n=69, r=0.255, P<0.05$; Figure 1), between LLF and $\mathrm{XO}(\mathrm{U} / \mathrm{L} ; \mathrm{n}=69, \mathrm{r}=0.244, \mathrm{P}<0.05$; Figure 2), and between MDA $(\mu \mathrm{mol} / \mathrm{L})$ and GPx $(\mathrm{U} / \mathrm{L} ; \mathrm{n}=69, \mathrm{r}=0.250, \mathrm{P}<0.05$; Figure 3) was also found in serum of patients with hypertension. In the group of patients with ARC, HT, and DM, there was a positive correlation $(r=0.459, P<0.05)$ between the activity of GPx $(\mathrm{U} / \mathrm{L})$ and MDA $(\mu \mathrm{mol} / \mathrm{L})$.

\section{Discussion}

It is well known that, at low physiological levels, ROS play important roles in maintenance of vascular tone, and

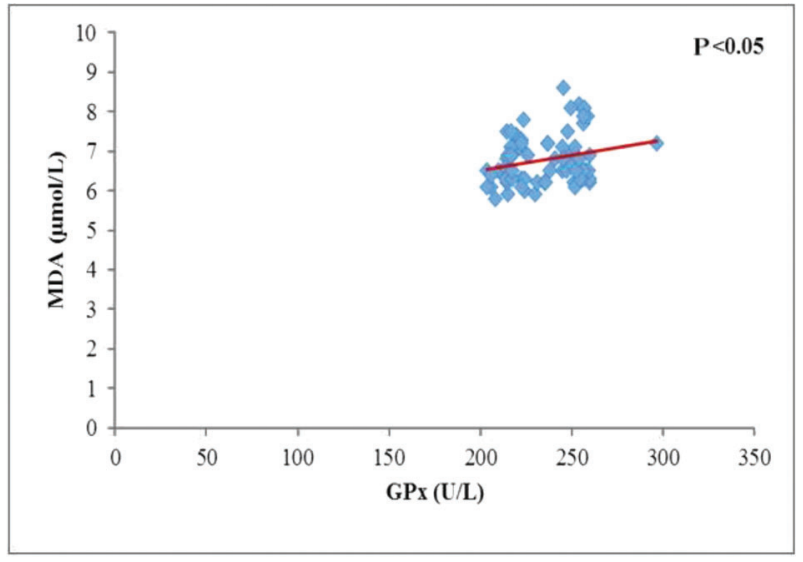

Figure 3. Correlation between malondialdehyde (MDA) and glutathione peroxidase (GPx) activity in serum of patients with hypertension and age-related cataract $(n=69, r=0.250, P<0.05)$.

that endothelium-derived NO, synthesized by constitutively expressed NOx, acts as the major vasodilator substance. On the other hand, increased formation or impaired elimination of ROS, and consequent oxidative stress have been implicated in vascular wall dysfunction and hypertension $(4,18,19)$ as well as in physiological ageing and in agerelated diseases, including ARC (1). Moreover, populationbased studies conducted in the past decade indicate that hypertension can increase the risk of ARC development (3).

Although the exact mechanism(s) of how hypertension enhances cataractogenesis is yet to be established, constantly increased blood pressure is often associated with systemic inflammation, dysregulation of glycemic control, dys- and hyperlipidemia, obesity, and oxidative stress (20). Accordingly, biomarkers of lipid oxidative damage, such as MDA and LLF, were significantly increased in hypertensive compared to normotensive ARC patients, especially in patients with co-existing diabetes. These results are consistent with a previously reported effect of hypertension on serum MDA levels (19), and with experimental evidence that systemic hypertension can modulate electrolyte homeostasis and increase MDA at both systemic levels and within lenses (21).

In the study of Khan et al., enzymatic as well as nonenzymatic antioxidants were depleted in hypertension (21), while in our study GPx activity was increased, especially in patients with co-existing diabetes. Our results were similar to Sreeja et al. (22), who reported significantly higher lens GPx activity in hypertensive compared to normotensive ARC patients. Literature data regarding effects of blood pressure on GPx activity in non-cataract subjects are also inconsistent, and erythrocyte enzyme activity was found unchanged (23) and even decreased (19), compared to normotensive controls. Although erythrocyte and plasma GPx are distinctive isoforms and thus might be differentially regulated, our results suggest that higher plasma GPx activity in hypertensive ARC could be an adaptive 
response to chronically increased systemic oxidative stress. Moreover, the significant correlation between GPx and MDA levels in HT and in HT and diabetic ARC group in our study further corroborate our assumption. In addition, decreased total -SH groups, FRAP, and SOD argue for intensive systemic oxidative stress in hypertensive ARC patients.

We have previously shown that increased XO expression may intensify oxidative stress at both lens and systemic levels, probably contributing to earlier development of ARC in diabetic subjects (9). Our current results further extend this and observations of others $(24,25)$ that increased serum XO activity is significantly associated with higher degree of oxidative damage and the development of microvascular and macrovascular complications in diabetics. As presented, compared to the normotensive ARC group, patients in the hypertensive ARC group had significantly increased $\mathrm{XO}$ activity, and an additional enhancement of $\mathrm{XO}$ activity was recorded in diabetic and hypertensive ARC patients. In addition, serum XO was higher in hypertensive and diabetic ARC patients, compared to hypertensive ARC patients without diabetes.

Human endothelial cells contain cytoplasmic and membrane-bound $\mathrm{XO}$, capable of producing $\mathrm{O}_{2}{ }^{\bullet-}$ and $\mathrm{H}_{2} \mathrm{O}_{2}$, depending on whether the substrate is xanthine or hypoxanthine. In circulation, XO can also produce ROS, thereby imposing injury to vascular endothelial and other cells in close proximity, for example adhered neutrophils. The reaction between $\mathrm{O}_{2}{ }^{\bullet-}$ and $\mathrm{NO}$ yields peroxynitrite, which is a powerful oxidant involved in nitration of tyrosine residues in proteins, also reported in hypertension and cardiovascular diseases (4). In addition, this reaction deprives local and systemic levels of vasodilator NO leading to endothelial dysfunction (20). Moreover, previous studies have shown that systemic $\mathrm{XO}$ activity was closely correlated to mean arterial pressure (26), and that inhibition of XO can normalize blood pressure in adolescents diagnosed with hypertension (27).

Increased XO activity was probably affected by the presence of hyperlipidemia and hypercholesterolemia in our study. In fact, the ARC with hypertension group had significantly higher concentrations of triglycerides, total cholesterol, and LDL-cholesterol levels than those with ARC only. Hypercholesterolemia is often associated with local hypoxia of the blood vessel walls, favoring the conversion of endothelial xanthine dehydrogenase to $\mathrm{XO}$ form. Also, hyperlipidemia and hypercholesterolemia can alter the function and/or expression of glycosaminoglycan $\mathrm{XO}$ receptors thereby enhancing accumulation of $\mathrm{XO}$ within the vascular wall. A study by Ohara et al. showed that blood vessels of cholesterol-rich diet fed animals produced

\section{References}

1. Kisic $B$, Miric D, Zoric L, llic A. Role of lipid peroxidation in the pathogenesis of age-related cataract. I: Angel Catala three times more $\mathrm{O}_{2}{ }^{--}$than normal (28), while in another study, XO inhibitors improved endothelial function in hypercholesterolemic rabbits (29).

Previous studies have demonstrated that $\mathrm{XO}$ can also act as a modulator of innate immune response through induction of pro-inflammatory cytokine synthesis and activation of neutrophils and macrophages, contributing to atherosclerosis development (30). Upon activation, neutrophils release some of their MPO from azurophilic granules into the blood. MPO is a pro-oxidant enzyme that catalyzes oxidation of chlorine ions by hydrogen peroxide to hypochlorite, which is a strong oxidizing agent. MPOderived oxidants present in the vasculature can further react with NO thereby reducing its availability, and probably contributing to vascular dysfunction and hypertension (31). Accordingly, serum MPO activity was significantly higher in hypertensive ARC patients in the current study. It can be assumed that increased activity of $\mathrm{XO}$ in hypertension and consequently greater production of $\mathrm{O}_{2}{ }^{\bullet-}$ could have some impact on activation of phagocytes and the release of MPO into extracellular space. It was previously demonstrated that $\mathrm{O}_{2}{ }^{--}$has an important role in regulation of MPO catalytic cycles, as it allows uninterrupted development of the chlorinating MPO cycle, thus intensifying oxidative damage (32). MPO-derived oxidants can damage the vascular wall constituents and reduce the elasticity. Also, MPO-derived oxidants can initiate lipid peroxidation as they readily react with polyunsaturated fatty acids generating oxidized fluorescent products (33). Accordingly, there was a significant positive correlation between the level of LLF and MPO activity, which probably reflects a prolonged pro-oxidant activity of MPO in patients with hypertension.

Results of our current study indicated that hypertension was associated with increased systemic activity of pro-oxidant enzymes XO and MPO in patients with ARC. We have also shown that endogenous antioxidant defense mechanisms were dysregulated in ARC patients with hypertension, as plasma GPx was upregulated, while the other antioxidants, including total thiol groups, SOD and FRAP, were significantly reduced. These results indicate that hypertension promoted oxidative stress in ARC patients. In such conditions, the supply of antioxidants and vitamins to eye tissues may be insufficient to protect the eye lens from further oxidative modifications, thus contributing to the development of ARC.

\section{Acknowledgments}

This work was funded in part by the Ministry of Science and Technology of Republic of Serbia, Grant No. 145112.

(Editor), Lipid peroxidation. London: Intech; 2012. p 457482, doi: $10.5772 / 45942$ 
2. Chang JR, Koo E, Agron E, Hallak J, Clemons T, Azar D, et al. Risk factors associated with incident cataracts and cataract surgery in the Age-Related Eye Disease Study (ARDES). ARDES Report No. 32. Ophthalmology 2011; 118: 2113-2119, doi: 10.1016/j.ophtha.2011.03.032.

3. Yu X, Lyu D, Dong X, He J, Yao K. Hypertension and risk of cataract: A meta-analysis. PLoS One 2014; 9: e114012, doi: 10.1371/journal.pone.0114012.

4. Touyz RM. Reactive oxygen species, vascular oxidative stress, and redox signaling in hypertension: what is the clinical significance? Hypertension 2004; 44: 248-252, doi: 10.1161/01.HYP.0000138070.47616.9d.

5. DeLano FA, Parks DA, Ruedi JM, Babior BM, Schmid-Schönbein GW. Microvascular display of xanthine oxidase and NADPH oxidase in the spontaneously hypertensive rat. Microcirculation 2006; 13: 551-566, doi: 10.1080/10739680600885152.

6. Pandey NR, Kaur G, Chandra M, Sanwal GG, Misra MK. Enzymatic oxidant and antioxidants of human blood platelets in unstable angina and myocardial infarction. Int $J$ Cardiol 2000; 76: 33-38, doi: 10.1016/S0167-5273(00)00344-2.

7. Suzuki H, DeLano FA, Parks DA, Jamshidi N, Granger ND, Ishii $\mathrm{H}$, et al. Xanthine oxidase activity associated with arterial blood pressure in spontaneously hypertensive rats. Proc Natl Acad Sci U S A 1998; 95: 4754-4759, doi: 10.1073/pnas.95.8.4754.

8. Newaz MA, Adeeb NN, Muslim N, Razak TA, Htut NN. Uric acid, xanthine oxidase and other risk factors of hypertension in normotensive subjects. Clin Exp Hypertens 1996; 18: 1035-1050, doi: 10.3109/10641969609081033.

9. Miric DJ, Kisic BB, Zoric LD, Mitic RV, Miric BM, Dragojevic IM. Xanthine oxidase and lens oxidative stress markers in diabetic and senile cataract patients. J Diabet Complicat 2013; 27: 171-176, doi: 10.1016/j.jdiacomp.2012.09.005.

10. Ledwozyw A, Michalak B, Stepien A, Kadziolka A. The relationship between plasma triglicerides, cholesterol, total lipids and lipid peroxidation products during human atherosclerosis. Clin Chim Acta 1986; 155: 275-284, doi: 10.1016/ 0009-8981(86)90247-0.

11. Tsuchida M, Miura T, Mizutani K, Aibara K. Fluorescent substances in mouse and human sera as a parameter of in vivo lipid peroxidation Biochim Biophys Acta 1985; 834: 196-204, doi: 10.1016/0005-2760(85)90156-0.

12. Roussos GG. Xanthine oxidase from bovine small intestine. Methods Enzymol 1967; 12(Part A): 5-16, doi: 10.1016/ S0076-6879(67)12005-3.

13. Metcalf JA, Gallin JI, Nauseef WM, Root RK. Myeloperoxidase functional assays. In: Laboratory Manual of Neutrophil Function. New York, Raven Press 1986; pp. 150-151.

14. Misra HP, Fridovich I. The role of superoxide anion in the autoxidation of epinephrine and a simple assay for superoxide dismutase. J Biol Chem 1972; 247: 3170-3175.

15. Chin PTY, Stults FH, Tapell AL. Purification of rat lung soluble glutathione peroxidase. Biochem Biophys Acta 1976; 445: 558-666, doi: 10.1016/0005-2744(76)90110-8.

16. Jocelyn PC. Spectrophotometric assay of tiols. Methods Enzymol 1987; 143: 44-67, doi: 10.1016/0076-6879(87)43013-9.

17. Benzie IF, Strain JJ. The ferric reducing ability of plasma (FRAP) as a measure of "antioxidant power": The FRAP assay. Anal Biochem 1996; 239: 70-76, doi: 10.1006/abio.1996.0292.

18. Redón J, Oliva MR, Tormos C, Giner V, Chaves J, Iradi A, et al. Antioxidant activities and oxidative stress byproducts in human hypertension. Hypertension 2003; 41: 1096-1101, doi: 10.1161/01.HYP.0000068370.21009.38.

19. Rodrigo R, Prat H, Passalacqua W, Araya J, Guichard C, Bachler JP. Relationship between oxidative stress and essential hypertension. Hypertens Res 2007; 30: 1159-1167, doi: 10.1291/hypres.30.1159.

20. Dinh QN, Drummond GR, Sobey CG, Crissobolis S. Roles of inflammation, oxidative stress, and vascular dysfunction in hypertension. Biol Med Res Int 2014, doi: 10.1155/2014/ 406960.

21. Khan SA, Choudhary R, Singh A, Bodakhe SH. Hypertension potentiates cataractogenesis in rat eye through modulation of oxidative stress and electrolyte homeostasis. J Curr Ophthalmol 2016; 28: 123-130, doi: 10.1016/j.joco. 2016.05.001.

22. Sreeja S, Jeyanthi GP, Gayathiri Devi S. Status of enzymatic antioxidants in eye lens extracted from cataractous subjects. Int J Pharm Pharm Sci 2015; 7: 139-142.

23. Rybka J, Kupczyk D, Kędziora-Kornatowska K, Motyl J, Czuczejko J, et al. Glutathione-related antioxidant defense system in elderly patients treated for hypertension. Cardiovasc Toxicol 2011; 11: 1-9, doi: 10.1007/s12012-010-9096-5.

24. Cosić $V$, Antić $S$, Pesić $M$, Jovanović $O$, Kundalić $S$, Djordjević VB. Monotherapy with metformin: does it improve hypoxia in type 2 diabetic patients? Clin Chem Lab Med 2001; 39: 818-821.

25. Desco MC, Asensi M, Márquez R, Martínez-Valls J, Vento $\mathrm{M}$, Pallardó FV, et al. Xanthine oxidase is involved in free radical production in type 1 diabetes: protection by allopurinol. Diabetes 2002; 51: 1118-1124, doi: 10.2337/diabetes.51.4.1118.

26. Newaz MA, Adeeb NN, Muslim N, Razak TA, Htut NN. Uric acid, xanthine oxidase and other risk factors of hypertension in normotensive subjects. Clin Exp Hypertens 1996; 18: 1035-1050, doi: 10.3109/10641969609081033.

27. Feig DI, Soletsky B, Johnson RJ. Effect of allopurinol on blood pressure of adolescents with newly diagnosed essential hypertension: a randomized trial. JAMA 2008; 300: 924-932, doi: 10.1001/jama.300.8.924.

28. Ohara Y, Peterson TE, Harrison DG. Hypercholesterolemia increases endothelial superoxide anion production. J Clin Invest 1993; 91: 2546-2551, doi: 10.1172/JCl116491.

29. White CR, Darley-Usmar V, Berrington WR, McAdams M, Gore JZ, Thompson JA, et al. Circulating plasma xanthine oxidase contributes to vascular dysfunction in hypercholesterolemic rabbits. Proc Natl Acad Sci U S A 1996; 93: 87458749, doi: 10.1073/pnas.93.16.8745.

30. Batteli MG, Polito L, Bolognesi A. Xanthine oxidoreductase in atherosclerosis pathogenesis: Not only oxidative stress. Atherosclerosis 2014; 237: 562-567, doi: 10.1016/j.athero sclerosis.2014.10.006.

31. Van der Zwan LP, Scheffer PG, Dekker JM, Stehouwer CD, Heine RJ, Teerlink T. Hyperglycemia and oxidative stress strengthen the association between myeloperoxidase and blood pressure. Hypertension 2010; 55: 1366-1372, doi: 10.1161/HYPERTENSIONAHA.109.147231.

32. Davies MJ. Myeloperoxidase-derived oxidation: mechanisms of biological damage and its prevention. $J$ Clin Biochem Nutr 2011; 48: 8-19, doi: 10.3164/jcbn.11-006FR.

33. Panasenko OM. The mechanism of hypochlorite-induced lipid peroxidation. BioFactors 1997; 6: 181-190, doi: 10.1002/ biof.5520060212. 